\title{
Reflexivity and Translation in Cross-Cultural Ethnographic Research
}

\author{
Carmen Valero-Garcés \\ University of Alcalá- FITISPos \\ E-mail: carmen.valero@uah.es
}

Received: July 14, 2021

Accepted: August 9, 2021

Published: August 20, 2021

doi:10.5296/ijl.v13i4.18952

URL: https://doi.org/10.5296/ijl.v13i4.18952

\begin{abstract}
The main aim of this article is to examine the role of translation in cross-cultural ethnographic research dealing with environmental texts. The main focus is on the analysis of linguistic issues that arise during field work when different languages and cultures that the ethnographer may not be familiar with come together. The study follows a qualitative methodology based on the analyses of ethnographer-researchers' reflections and the translation of their notes as well as well as certain issues that arise when writing research between two languages and cultures when the ethnographer may or may not be familiar with.
\end{abstract}

Keywords: Ethnography, Reflexivity, Translation, Interpretation, Transcription, Crosscultural research

\section{Introduction. Translation and Ethnography}

Translation is often ignored in Ethnography despite being a common practice in which researchers themselves assume the role of translators without reflecting on the importance of this element in the overall configuration of the research process.

The number of research papers written and published in a language other than that of the researcher is on the rise, as are the number of instances where translation is necessary. In 2014,Ecozon@(Ecozon@, spring 2014) devoted a special issue to the translation of environmental texts. In this issue, emphasis was placed on three important elements that come into play when translating a text from one language to another: namely, the source text (ST), the translator, and the target text or translated text (TT). Each of these elements in turn contains other elements that may influence in one way or another the result or TT.

The main aim of Ecozon@ 2014 issue was to draw attention to 'translation', understood as a vehicle for communication between different languages and systems (interlingual, intralingual and intersemiotic translation) to offer different perspectives on environmental 
issues and suggesting themes for reflection. In the introduction to the volume, attention was called to the importance of the spectators' reactions as influenced by their culture, traditions, and knowledge. An example given by the author included the different effects that the arid landscape of Southern Europe produced in Northern Europe visitors. What was normal for its inhabitants, was exotic for visitors; or the same thing happens when we think of the desert of Arizona and the frozen landscape of Alaska when visited by tourists; or when we try to "translate"/"interpret" the language of other species (sounds or movements of animals or plants) to words. What is usual becomes novel and vice versa (Valero-Garcés 2014).

Reflecting on these examples leads us to ask ourselves a series of questions as receivers of these TTs: how do we recreate these images and sensations into another language for new readers? How can we make these readers feel like real spectators who are capable of capturing the full force of the landscape that the author of a text in a language other than their own has described? How do we cross the borders of knowledge from within and outside of the same language? How do we neutralise, or on the contrary, magnify the rhetorical power of discourse when being transported to another reality? What does the reader of a TT know about the ST or about the author? What does the author of a text know about its translation and its new audience? What do we know about the translator, the architect of this transfer? Has the translator made him/herself known, or does he/she remain anonymous? Has the translator sought to work in collaboration with the author? Has the translator prioritised his or her ethical principles over those of the author of the ST? Has the translator tried to get closer to the new culture or have they opted to remain closer to the ST?

The literature to answer these questions is vast in the field of Translation Studies. I will just mention two examples. A World Atlas of Translation (2019) by editors Gambier and Stecconi is a good source to approach translation in the different historical, cultural, and linguistic traditions of the world beyond the Western world. It is also useful to learn about the uses that have been given to translation, the distance that exists in the conceptualisation of translation in the different traditions or the multiple questions it raises in both practice and theory. In Border Crossings Translation Studies and Other Disciplines (Gambier and Van Doorslaer, 2016) the editors include a series of studies written by specialists from other disciplines traditionally interested in translation such as Computational Linguistics, History and Comparative Literature, and Communication Studies, as well as studies by less traditional interlocutors such as specialists in Biosemiotics, Games Localisation or Gender Studies. However, there is no mention of cross-cultural Ethnography or Anthropology, disciplines in which it is common practice for researchers themselves to take on the role of translator.

The main aim of this article is to examine the role of translation in cross-cultural ethnographic research. The study follows a qualitative methodology based on the analysis of ethnographers' reflections and the translation of their notes, as well as certain issues that arise when writing research between two languages and cultures when the ethnographer may or may not be familiar with.

The starting point for this research is the consideration that by bringing translation to the fore and analysing it as a part of the research process in cross-cultural ethnography, we can 
enhance the researcher's reflexivity about the role of translation as a transfer of meaning from one spatio-temporal context to another, and also give greater credibility and objectivity to the research.

The inclusion of translation in the researcher's methodology will enable us to delve into the idea of the ethnographer as an omnipresent "connoisseur" (Tremlett, 2009). It will also allow us to discuss the unavoidable betrayal (or creativity) involved in translation, which allows us to convey the richness of the connotations contained, for example, in the researcher's notes rather than ignoring or suppressing them (Crane et al (2009).

\section{Reflexivity, Ethnography, and Translation}

The challenges that arise when several languages and cultures come into play are an issue that is not always resolved or taken into account by researchers in cross-cultural ethnographic research. In his study on the translation of interviews in sociological research and the role of the researcher-translator, Poblete (2009: 631) emphasises the lack of rigor in their treatment and suggests that the interventions of research participants in other languages should be considered as discursive quotations and be paraphrased, commented on, or translated and referred to as quotations.

Presenting notes and accounts in other languages as part of the material collected by the researchers in the language in which they display their research hides the involvement of the researcher as a translator and raises two issues that are difficult to hide. Poblete summarises as follows: 1. Need to account for the discourse of those researched (the Other), 2. Obligation to be accountable to the academic world.

With regard to the first point, it is common that, although the informants speak a language, they are simply referred to as speakers of another language, or they ignore this fact, and are presented as speaking the same language as the researcher or the language in which the research is to be presented. As for the second point, it often happens that, in addition to ignoring translation, the discourse of the research participants is subject to the protocols of academic writing, which casts doubts on the scientific rigour that is pursued in all research carried out halfway between two linguistic worlds- and therefore, between two symbolic worlds.

This is a twofold process in which, firstly, the field notes must be interpreted and, secondly, the notes must be translated into another language and culture. Poblete (2009: 646) gives the example of sociological interviews when the notes are translated into the other language by the researcher himself. The researcher therefore takes on the dual role of both researcher and translator, leaving the latter invisible and disregarding the work of the translator and his or her profession, and concludes:

The specific case of translation of sociological interviews highlights the fact that citation, as a privileged discursive strategy, obscures the process of research itself, by rendering invisible the involvement of the researcher as translator. In effect, when we pretend that our informants speak French when they actually speak Spanish, it would 
seem we are ignoring the fact (but are we really ignoring it?) that any multilingual research is in itself an act of translation. (Poblete 2009: 644).

Poblete thus highlights the authority of the researcher in constructing the text. At the same time, he draws attention to the responsibility of the researcher-translator when it comes to making the participant's words visible in the same way that they were pronounced and not mediated. He advocates the use of the quotation strategy- i.e., the ST and its translation in the body of the text or as a footnote quotation. If this is not the case, the researcher-translator, when presenting the translated interviews, produces an illusion of equivalence between the communicative situation of the original and that of the academic audience receiving their research.

This communicative fiction involves incorporating the very act of translation discourse into an almost routine action for the researcher. However, the researcher-translator partakes in a dual process of interpretation: interpreting the message he/she receives, and reinterpreting it for his/her audience. In this way, the researcher-translator does not only takes part in what the participant (the Other) said, but also in the way in which the Other is interpreted - that is- the way the researcher-translator thinks that voice could be understood by foreign readers. Through the analysis of two different linguistic and cultural worlds, the researcher-translator looks for a meeting point between the interviewees and the final recipients. These two construct a virtual space in which, through mediation by the researcher-translator, the reader can gain access to the world of the research participants.

According to Temple (2005), this difficult process of restructuring information can result in the loss of meaning or the silencing of translation as a part of the methodology in the search for a coherent and clear narrative, or it can also cause anxiety or empathy in the researcher.

As we move towards an increasingly multicultural and multilingual society, more and more researchers are working with people who speak different languages and feel obliged (or confident they will be able to do so) to take on the double/triple role of researcher-interpreter and translator in order to conduct an interview or manage a focus group, and then transform their notes into written material in the other language (translate) to provide written reports in their language, or even in English if it is not their language, - because English is the language par excellence of the academic and research world. As a result, we would then be dealing with translation into a third language which could lead us to the issue of directionality and the debate on direct and reverse translation (Pokorn 2000, Hunziker Heeb 2016), a topic that is beyond the scope of this paper.

It could also be the case that all these participants are reduced to a single researcher who takes on the different roles of, amongst others, author of the final written text, researcher taking field notes and interviewing research participants, transcriber of an oral account, and translator of their own notes and the final report.

Temple (2005) writes:

There is no attempt within the research to discuss whether there are possible differences in word or concept meaning. People from language communities are employed as 
interpreters to transmit words across languages or as researchers to do the interviews themselves, translate them and then pass the English version to the researchers. Issues around representation and language are not addressed.

Temple (2005: 9) draws attention to two aspects that are often overlooked: 1. Knowing the language does not necessarily imply knowing the culture, and 2. A written text is subject to written conventions. Some considerations follow.

1. Knowing the language does not necessarily imply knowing the culture.

With regard to this first point, the literature on the unquestionable relations between language and culture in practice and theory both outside and within Translation Studies is abundant (Hung, 2005). In fact, the same language can serve as a vehicle of expression for many cultures, for example, the Indian culture and the use of English or the Amerindian cultures and the use of Spanish: language and some cultural traits are shared; however, it is more what distinguishes them at that level as opposed to what brings them together (Richter and Song, 2005).

When translation is overlooked, then there are three aspects of representation that are also overlooked. Firstly, there is the question concerning what perspective to use; secondly, there is the issue of who takes on the role of translator: the researcher or the research participant; and thirdly, the topic of the nature of the text when presenting the research is unresolved.

With regard to the first point, translation is not just a matter of reproducing words, but rather reproducing meanings from one language and culture to a new readership. The translator is constantly faced with dilemmas and their decision making reflects different positions. Venuti (1998) speaks about "domestication" and "foreignization"; Levine (1991) speaks about the translator-collaborator"; Loffredo and Perteghella (2006) see translation as an activity closely related to creative writing; Tymoczko (2007) draws attention to the influence of ideologies on the translator in the translated text; and Maier (2007) speaks about the conscious intervention of the translator as an ethical agent who contributes to social change, describing the translator as a "collaborator".

Regarding the second point- who takes on the role of translator- traditional ethnography has generally shown a hierarchical relationship between the researcher and the participant. It is usually based on the distinction between the privileged, white, Western researcher who moves to non-Western or unexplored and exotic areas to make observations, and the less powerful, non-white, non-Western research participants. In general, the researcher and participant are observed to have different ethnical backgrounds, and the studies are judged to be influenced by imperial power and colonial management, as well as a tendency to consider non-white populations as a researched "Other" (Alexander, 2006; Sharma et al., 1996).

As for the third point- the role that researchers (anthropologists and ethnographers) - take on in the representation of cultures- it has become a subject of debate. Just as Ali (2006) points out, power relations between the researcher and participant are, in fact, quite inevitable and manifest themselves in multiple ways during the research process. This issue has been one of the key methodological issues in ethnographic research and has raised questions about the 
researcher as an initiated researcher -- native versus non-initiated researcher - foreigner. Kim (2012) speaks about the native ethnographer who begins to have greater visibility, and Gallagher (2000) and Sin (2007) draw attention to the experiences of ethnic minority researchers in the studies of whites. Osanami and Ngeh (2018), on the other hand, question what happens when non-white people interview a predominately white population, or people from the same race, but from a different ethical background.

\section{The written text is subject to certain conventions.}

Transforming an oral text or field notes into a scientific text written in an academic style, requires a number of changes in the way in which it is presented and received. This transformation involves accepting a series of conventions specific to this textual typology. At present, these conventions are largely imposed by English, the lingua franca of scientific communication. If the text also has to be translated, the restrictions inherent to the translation of the text should be added. As Tavalán (2018: 12) points out: "Even though it is generally known that a translation is the reflection of a source text (ST) into an equivalent target text (TT), translation is not as straightforward as it may seem." She also states: "There are a series of strategies that need to be known and practiced, a fair amount of linguistic rules (...), and various other concepts related to equivalence and non-equivalence at different levels need to be understood". Therefore, a literal, precise translation -with the help of a dictionary - is just as impossible as a single translation of a text. However, there is little mention of this issue in ethnographic research.

This line of discussion leads to the consideration of some researchers (Müller 2007, Temple 2005) that bringing translation to the foreground and viewing it as a part of the research process would enhance reflexivity about the objectivity of the research by proving that "translations constantly suffer from not being able to convey the richness of connotations" during the act of transfer (Müller 2007: 207). Temple (2005), on the other hand, argues that failure to take translation into account raises the issue of the lack of "full objectivity" in the research and questions the figure of the ethnographer as an omnipresent "connoisseur". Tremlett (2009: 85), however, goes even further and speaks of the unavoidable betrayal (or creativity) involved in translation in the consideration of the ethnographer as an omnipresent "connoisseur".

Sturge (2014) insists once more on the need to recognise translation as an element of ethnographic research. She draws attention to the fact that ethnographic research in English relies heavily on translation and complains about the lack of attention given to specific strategies for transferring information from one language to another, which weakens the objectivity of ethnography. In her study titled "Translation strategies in Ethnography", she explores aspects related to translation and the different strategies used to overcome the unequal relations between source and target language and cultures. This enables her to show the power of translation and to admit that the reflexive mode of translation in postmodern ethnography can undermine the authority of both the ethnographer and the translated text.

In the Method section, Sturge describes in detail how the study was conducted, including conceptual and operational definitions of the variables used in the study. Assuming that 
different types of studies will rely on different methodologies, she shows that a complete description of the method will enable the reader to evaluate the appropriateness of used method and the reliability and validity of the results. It will also allow experienced investigators to replicate the study if the manuscript is an update of an ongoing or earlier study and the method has been published in detail elsewhere. Therefore, the reader may be referred to that source and simply give a brief synopsis of the method in this section.

\section{Ethnographic Research and Translation. Examples}

As a way to illustrate some of the dilemmas explained above in this section, I will look at several ethnographic research studies where translation is part of the methodology. The first study is titled "Ethnographer location and the politics of translation: researching one's own group in a host country" by Kim (2012); the second one is titled "On being a foreign body in the field, or how reflexivity around translation can take us beyond language" by Anna Krzywoszynska (2015); and the third study is the book titled Nature in translation (2015) by Satsuka (2014).

A closer look at the work by Kim reveals an auto ethnographic study on South Korean immigrants in the United Kingdom. The author, a South Korean researcher in England, shows us how the lack of ethnically homogeneous situations due to differences in ethnicity, or because they do not live in the same country, or share the same language and culture, make it necessary to incorporate translation into the research process, as well as two other important elements to understand the position occupied by the researcher. These are the position assigned to the target readers, and the power of representation that the author of the final text has.

Kim (2012: 138) draws attention to the wide range of readers that the researcher-translator faces and how their decisions shape the potential reader in mind, which may also be influenced by the power relations that may arise between the researcher-translator and the readers: “(...) when an author transports participants' lives into the text, he or she might have in mind certain important potential readers. Such target readers may include professional colleagues, reviewers, and editors, as well as a broad range of general audiences"

Kim concludes by saying:

Power relationships can be found in the relations between a translator (researcher) and audience. It is impossible for scholars to be immune to reviewers' comments and other readers' reactions as scholars are expected to make their work understandable and acceptable (Kim 2012:138).

In other words, the researcher - writer is conditioned not only by social or cultural conventions, but also by his/her relationship with the TT readers. It is the writer and the people for whom the research is being written that often determine the tone of writing, purpose, and the characteristics of the researcher. In this regard, Temple and Young (2004: 178)) ask whether translation is only about introducing the marginalised (or minority) to the majority, and whether it is only a tool to present non-Western culture to Western audiences. These are questions that require answering in the future outside of this paper. 
The second example is the article by Krzywoszynska (2015) and is also another autobiographical article: "I explore a personal experience of investigating the local relationship between expression and experience in ethnographic fieldwork".

Krzywoszynska uses participatory ethnographic methods to explore the relationship between the discourses of the organic wine industry and the daily practices in vineyard cultivation and winemaking. For that reason, she worked in four vineyards and wineries in Northern Italy. This experience allowed her to undertake a period of training as a winegrower, from which she then drew material for her research. This material consists of audio and video recordings, which she then transcribed- conscious of her insufficient knowledge of specialised wine vocabulary in the language-, in this case Italian, because- as the author points out - despite having a good command of the Italian language, she nonetheless missed or did not understand certain technical wine terms, dialectal terms or local accents. She therefore decided to record not only scheduled interviews, but also everyday conversations, which she later translated and transcribed in the evening time.

Krzywoszynska takes on the role of the researcher-translator, but far from omitting or overlooking this circumstance, she discovered that it was the conscious act of translating her field material that forced her to analyse her position concerning the object of research. This led her to confront the challenges of transferring the information she had from one language to another. It also prompted her to reflect on the process of transferring meaning in winemaking practice, while at the same time acquiring knowledge of vine pruning on an equal footing with other young Italian workers (with the exception of the researcher whose mother tongue was not Italian).

As an example of this, she describes and transcribes part of a video recording that she took on one of her first days of work to illustrate her first attempt at learning how to prune. With this example she tries to show the limits of verbal explanation that she faced in her attempts to learn the work of vine pruning:

Finally a day without snow. We meet at eight o' clock to go the vineyard to prune. (...) there is Virgilio, who came especially to give some additional instructions to the vineyard workers who have been pruning the vines for a few weeks now. We stand around in a loose group (...) Virgilio is speaking, holding a cut piece of a pruned vine in his hand:

'Questo qua, nonostante, son tanti motivi, uno che nonostante fosse stato corto questo non è, cosi cosi, l'anno scorso chi ha potato ha fatto bene a lasciarlo perche ha tentato ancora di, no? Se no, sarebbe stato nel primo anno.'

Questo qua, nonostante, son tanti motivi, uno che nonostante fosse stato corto questo non è, cosi cosi, l'anno scorso chi ha potato ha fatto bene a lasciarlo perche ha tentato ancora di, no? Si no, sarebbe stato nel primo anno.] (her own translation)

As we can see, she combines the audio and video recordings in both languages- English and Italian-, as she did not feel confident with Italian and because she could listen to the 
recordings later on and reflect on how to translate them. The comment bellow illustrates how she feels:

Standing in the snowy vineyard that day, trying to make sense of Virgilio's instructions, I found myself brought to tears by my incompetence. I could make out the sounds, I could make out the individual words even, but I could not make out the meaning, I could not 'make sense' of what he was saying. (2015: 315).

She translates the text from Italian to English but does not feel satisfied with her version, which is as follows: "This here, there are many things you have to think about. One is that, even though it was short, it was more or less all right, whoever pruned it last year did the right thing leaving it, because it tried to, still, right? If not it would have been in the first year".

She describes her feelings as follows:

The words were all there, but the meaning was absent. I understood what Virgilio had said, but I did not understand what he was saying. Was this a failure of translation? I considered myself relatively fluent in Italian, and yet in the vineyards I was rendered dumb.

Krzywoszynska sees translation as a process of exploring meaning, and as such, is attentive to the moments in which meaning overflows what is said, and words fall short. For example, when participants would stutter, babble, or fall silent, or when she realised that she could not follow their conversation because they were speaking too fast or because she did not understand what they were saying. All of these include important areas of signification beyond language that the researcher must understand and be able to reflect on. She therefore argues that the first step in ethnographic research involving other languages is to understand the relationship between the researcher and the research participants, not the relationship between the researcher and their readers to whom they must convey their research in an understandable way. She writes: "The first stage of translation, then, is understanding. Faced with the enigmatic body of the vine, and the inexplicable speech of Virgilio, I did not understand".

The author, as we have indicated, did not know the specific vocabulary and technical terms used in Italian in the winemaking industry and after months of learning and going to the fields with the workers and following the lessons given by Virgilio, the instructor, she exclaims (2015: 317): "My ignorance, I continued to feel, was an inability to see the link between the word and the world."

She lacks experience, she lacks knowledge of the specific code or what she refers to as "a repository of meaning separate from practice"- to be able to move from practice (what she sees in the field) to the written code (words): "Over and over again in my evening translations, I was faced with the emptiness of words. I translated, but the words were not telling me anything. The meaning leaked out."

According to the author, this lack of meaning does not come from a lack of specific 
vocabulary because the translation of terms could be done using a dictionary or the internet. This lack of skill or ability to carry out the actions explained by the monitor is expressed as follows: “(...) I could not translate because I did not do"- she would say. Krzywoszynska (2001: 311) adds: "Translation in cross-cultural research, I argue, is less about the decoding of texts, and more about coming to understand a form of life." In her reflections on her research project, the author notes that night after night she tries to make sense of her translation, convinced that actions precede words and that words are not univocal, but can have different meanings in different contexts. This fact explains the difficulty, for example, in translating terms that look like synonyms or that do not exist in the other language ('terminological gaps' (Cabré 2004: 90)), and the need to use other strategies. Krzywoszynska questions the role of the 'omnipresent ethnographer'- or what she calls "an 'eye in the sky' ethnographic observer"- following Smith (1996) and warns of the consequences that this inclusion of a new element such as translation can have on traditional methodologies.

The third example that I would like to present that incorporates translation as an element of reflection and methodology is the work of the Japanese author Satsuka Nature in Translation, (2015) and her analysis of the Canadian Rocky Mountains through the lives, experiences, and perceptions of young Japanese people in Canada and its influence on Japanese tourism, and in the development of successful tour guides in the country.

In Nature in Translation, the author brings two different macro-conceptions of realities to the stage: East and West, reflected in two national cultures: Japan and Canada. From there she then analyses the ways in which the Canadian landscapes of Banff National Park in the Rocky Mountains are seen and translated by three young Japanese people for a Japanese audience.

Satsuka describes the different process that each one of these young people go through to firstly, assimilate and experience the landscapes and people in the Banff National Park in a language other than their mother tongue (in this case English), and secondly, to express these impressions in their mother tongue (Japanese) and for a specific audience (tour guides for a Japanese audience).

Satsuka reflects on the observations and notes made by these young people in their scientific work to realise that even if it is scientific language, it is neither as abstract nor as univocal as science would have us believe. She writes:

(...) tension between the treatment of ecological science as universal knowledge and the culturally constructed affective sensibilities caused puzzlement for the Japanese guides, who were trying to learn ecology as a shared language in the park and were being led to believe that scientific knowledge is culturally neutral and universally applicable to people with diverse backgrounds. (Satsuka 2015:194).

In the following paragraph, she explains her conception of cultural translation and defends its role as an element to be taken into account in ethnographic research: 
Japanese tour guides' work of cultural translation is, in part, the enactment of this desire, not to be in the world as objects of an exotic tourist gaze, but to achieve the position of subjects and to be recognized as actors with a unique set of perceptions and practices of engagement in the world. Responding to this legacy, the Japanese tour guides in Banff dealt with this desire and performatively constructed their subjectivities as Japanese cosmopolitans. (Satsuka 2015: 37-38).

In short, Satsuka, like Krzywoszynska and Kim, provides another example of how to explore the difficulties of linguistic expression when switching between languages.

\section{Main Conclusions}

This article deals with two main topics: reflexivity and translation as elements to consider in cross-cultural ethnographic research. Assuming that translation is not just merely a matter of linguistic transfer, but rather a process dependent on other factors to help transmit it, this paper is therefore intended to contribute to this debate by suggesting that translation offers a new opportunity for reflexivity in cross-cultural ethnographic research by alerting us to those dimensions in which meaning is made through something other than language, or even outside of language

With regard to reflexivity as a methodological element of research in the process of transferring field notes into a written scientific text, we have discussed attempts made to show its value as a tool for examining the impact of the researcher's position, perspective, and presence in their work as well as its influence on empowering others by giving them a voice, evaluating research processes, methods, and results.

With regard to translation, we have defended its inclusion as a methodological element in ethnographic research, thus echoing current trends towards its inclusion in an increasingly multilingual and globalised world. Through various examples we have tried to highlight some of the challenges that arise, the reflections they provoke, and the strategies used by their authors to promote interpersonal relationships and dynamics and to empower the researcher/translator/reader in order to open up a more radical and multidisciplinary awareness.

From different positions and cultures, the ethnographic studies by Kim, Krzywoszynska and Satsuka suggest that cross-cultural researchers are in a good position to contribute to the exploration of qualitative methods beyond representation, as the consideration of the process of translation and its accompanying elements can open up new areas of research. In their cross-cultural ethnographic research, all three authors provide methods of how to do this by incorporating the reflections of the cross-cultural researcher and the translator into their methodology.

Other examples of research that include participatory and reflective methods in their studies and bring in different approaches are, for example, the use of autoethnography (Lorimer 2006, Krzywoszynska 2015), psychoanalytical methods (Proudfoot 2010), or visual approaches (Laurier and Brown 2008; Laurier and Philo 2003). These cross-cultural researchers are also conscious of the fact that integrating translation into qualitative research in cross-cultural 
ethnography could open up new areas of meaning that would otherwise remain hidden.

In short, this is an exploratory study. Due to the small corpus of data used for the analysis, the conclusions are partial and cannot be generalized. However, the study may open new doors to explore in future work topics such as interdisciplinarity, bidirectionality in translation, the role(s) of the researcher working in multilingual environments, or collaborative translation to name but a few.

We live in an increasingly multicultural and multilingual society, consequently more and more ethnographic researchers are working with people who speak different languages. They often assume a double/triple role of researcher-interpreter and translator when conducting fieldwork. So these ethnographers might be working with at least three different languagestheir native language, the language of the focus group or interviewee, and even English- as the research language per excellence- if this is not their language. As a result, issues of non-professional interpreting and translation, or translation into a third language will contribute to expand existing knowledge on the issue of directionality and the debate on direct and reverse translation.

When assuming that any multilingual research is an act of translation, bringing translation to the foreground and viewing it as a part of the research process will enhance reflexivity about the objectivity of the research, and will allow researchers (anthropologists and ethnographers) to deep into issues around representation and language that are often overlooked. Issues such as the perspective used by the interpreter/translator- that is the researcher or the research participant-, the potential influence in the text, the representation of cultures, the introduction of marginalised (or minority) to the majority, or the inclusion of non-Western cultures to Western audience are unexplored topics beyond the scope of this paper, but subjects of debate for future research.

Exploring the consideration of the ethnographer as an omnipresent "connoisseur" and paying attention to the role of the professional translator/interpreter by giving attention to specific strategies used for transferring information from one language to another will also strength the objectivity of cross-cultural ethnographic research.

These are questions that require answering in the future outside of this paper. Research results could have an impact on traditional methodologies and will contribute to expand existing knowledge not only on different disciplines such as Cultural Studies, Translation and Interpreting Studies and Ethnography, but also to increase interdisciplinary and cooperation.

In short, the main conclusions of this research are to open up new avenues for future studies on the topic that will potentially contribute to existing knowledge.

\section{Acknowledgments}

Thanks for personal assistance, such as in manuscript preparation.

\section{References}

Alexander, C. (2006). Writing race: ethnography and difference. Ethnic and Racial Studies, 
29, 397-410.

Ali, S. (2006). Racializing research: managing power and politics?. Ethnic and Racial Studies, 29, 471-486.

Cabré, M. T. (2004). La terminología en la traducción especializada. In Gonzalo García, C., \& García Yebra, V. (Eds.), Manual de documentación y terminología para la traducción especializada (pp. 89-122). Madrid: Arco/Libros. Colección: Instrumenta Bibliológica.

Crane, L. G., Lombard, M. B., \& Tenz, E. M. (2009). More than just translation: challenges and opportunities in translingual research. Social Geography, 4, 39-46.

Gallagher, C. A. (2000). White like me? Methods, meaning, and manipulation in the field of white studies. In Twine F. W., \& Warren, J. W. (Eds.), Racing Research, Researching Race: Methodological Dilemmas in Critical Race Studies. New York: New York University Press.

Gambier, Y., \& Doorslaer, L. C. (Eds.) (2016). Border Crossings. Translation Studies and other disciplines. Amsterdam: John Benjamin.

Gambier, Y., \& Stecconi, U. (Eds.) (2019). A World Atlas of Translation. Amsterdam: J. Benjamins.

Hung, E. (Ed.) (2005). Translation and Cultural Change. Studies in History, Norms and Image-Projection. Amsterdam: John Benjamins.

Hunziker Heeb, A. (2016). Professional translators' self-concepts and directionality: indications from translation process research. The Journal of Specialised Translation, 25, 74-88.

Italiano, F. (2012). Translating geographies: The Navigatio Sancti Brendaniand its Venetian translation. Translation Studies, 5(1).

Kim, Y. J. (2012). Ethnographer location and the politics of translation: researching one's own group in a host country. Qualitative Research, 12, 131-46.

Krzywoszynska, A. (2015). On being a foreign body in the field, or how reflexivity around translation can take us beyond language. Area, 47, 3311-318.

Laurier, E., \& Brown, B. (2008). Rotating maps and readers: praxiological aspects of alignment and orientation. Transactions of the Institute of British Geographers, 33, 201-21.

Laurier, E., \& Philo, C. (2003). The region in the boot: mobilising lone subjects and multiple objects. Environment and Planning D: Society and Space, 21, 85-106.

Levine, S. (1991). The Subversive Scribe: Translating Latin American Fiction. Dalkey: Archive Scholarly.

Lieven, D., \& Gambier, Y. (Eds.) (2018). A History of Modern Translation Knowledge. Sources, concepts, effects. Amsterdam: John Benjamins. 


\section{Al Macrothink}

International Journal of Linguistics

ISSN 1948-5425

2021, Vol. 13, No. 4

Loffredo, E., \& Perteghella, M. (2006). Translation and Creativity: Perspectives on Creative Writing and Translation Studies. London: Continuum.

Lorimer, H. (2005). Cultural geography: the busyness of being 'morethan-representational'. Progress in Human Geography, 29, 83-94.

Maier, C. (2007). The Translator's Visibility: The Rights and Responsibilities Thereof. Ed. In Salama Carr, M. (Ed.), Translating and Interpreting Conflict (pp. 53-66). Amsterdam: Rodopi.

Müller, M. (2007). What's in a word? Problematizing translation between languages. Area, 39, 206-13.

Osanami, S., \& Ngeh, J. (2018). Reversing the gaze; methodological reflection from the perspective of racial-and-ethnic-minority researchers. Qualitative Research, 8(1), 3-18.

Poblete, L. (2009). Pretending they speak French: the disappearance of the sociologist as translator. Social Science Information, 48, 631-46.

Pokorn, N. (2000). The pros and cons of translating into a non-mother tongue: Theoretical bias and practical results. In Grosman, M., Kadric, M., Kovacic, I., \& Snell Hornby, M. (Eds), Translation into Non-Mother Tongues in Professional Practise and Training (pp. 71-79). Tübingen: Stauffenberg Verlag.

Proudfoot, J. (2010). Interviewing enjoyment, or the limits of dis-course. The Professional Geographer, 62, 507-18.

Richter, E., \& Song, B. (2005). Translating the Concept of 'Identity'. In Hung, E. (Ed.), Translation and Cultural Change. Studies in history, norms and image-projection (pp. 91-110). Amsterdam: John Benjamin.

Satsuka, S. (2015). Nature in Translation: Japanese Tourism Encounters the Canadian Rockies. Duke University Press.

Sharma, S., Hutnyk, J., \& Sharma A. (Eds.) (1996). Dis-Orienting Rhythms: The Politics of the New Asian Dance Music. London: Zed Press.

Sin, S. H. (2007). Ethnic-matching in qualitative research: reversing the gaze on 'white others' and 'white' as 'other'. Qualitative Research, 7, 477-499.

Smith, F. M. (1996) Problematising language: limitations and possibilities in 'foreign language' research. Area, 28, 160-6.

Sturges, K. (1997). Translation Strategies in Ethnography. The Translator, 3(1), 21-38.

Talavan, N. (2016). A Univertiy Handbook on Terminology and Specialized Translation. Madrid: UNED.

Temple, B. (2005) Nice and tidy: translation and representation. Sociological Research Online, $\quad$ 10(2). $\quad$ Retrieved $12 \quad$ April, 2018, from http://www.socresonline.org.uk/10/2/temple.html 


\section{Macrothink}

International Journal of Linguistics

ISSN 1948-5425

2021, Vol. 13, No. 4

Temple, B., \& Youn, A. (2004). Qualitative research and translation dilemmas. Qualitative Research, 4, 161-78.

Tremlett, A. (2009). Claims of 'knowing' in ethnography: realising anti-essentialism through a critical reflection on language acquisition in fieldwork. Graduate Journal of Social Science, 9, 63-85.

Twyman, C., Morrison, J., \& Sporton, D. (1999). The final fifth: autobiography, reflexivity and interpretation in cross-cultural research. Area, 31, 313-325.

Tymoczko, M. (2007). Enlarging Translation, Empowering Translators. Manchester: St. Jerome Publishing.

Valero-Garcés, C. (2014). Introduction: Translating Environmental Humanities. Ecozon@, European Journal of Literature, Culture and Environment, Vol 5, $\mathrm{n}^{\mathrm{o}} 1$ (2014). DOI: https://doi.org/10.37536/ECOZONA.2014.5.1.583.

Venuti, L. (1995). The Translator's Invisibility. A History of Translation (2nd ed.). London \& New York: Routledge.

\section{Copyrights}

Copyright for this article is retained by the author(s), with first publication rights granted to the journal.

This is an open-access article distributed under the terms and conditions of the Creative Commons Attribution license (http://creativecommons.org/licenses/by/4.0/) 